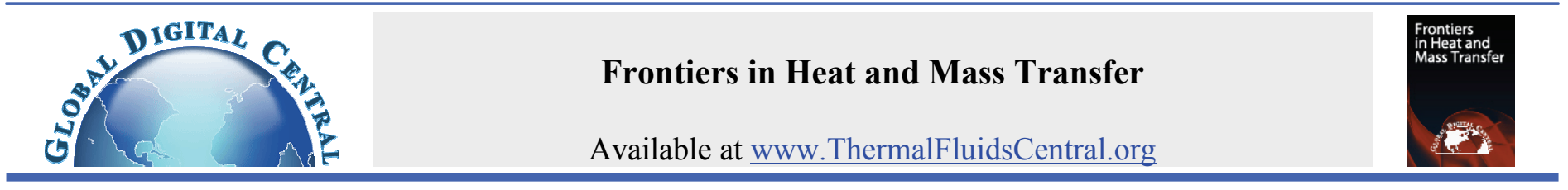

\title{
THE STUDY OF TEMPERATURE PROFILE INSIDE WAX DEPOSITION LAYER OF WAXY CRUDE OIL IN PIPELINE
}

\author{
Zhen Tian ${ }^{\mathrm{a}}$, Wenbo Jin ${ }^{\mathrm{a}}$, Lei Wang ${ }^{\mathrm{b}}$, Zhi Jin ${ }^{\mathrm{c}}$ \\ ${ }^{a}$ Petroleum and Natural Gas Engineering College, Southwest Petroleum University, Chengdu, Sichuan, 610500, China \\ ${ }^{b}$ The Second Oil Production Plant of Qinghai Oilfield, Haixi/Qinghai, 817500, China \\ ${ }^{c}$ Research Institute of Shaanxi Yanchang Petroleum(Group) Co, LTD, Xi'an/Shaanxi, 710075, China
}

\begin{abstract}
Taking the axial heat conduction of wax deposition layer into account, a two-dimensional heat transfer model of calculating the temperature profile inside wax deposition layer was deduced and established based on the energy balance equation, the finite difference method was used to solve this model, and the influence of axial heat conduction on the distribution law of temperature profile inside the wax deposition layer under different boundary conditions and thickness were discussed. The results showed that: Temperature profile inside wax deposition layer in middle region of testing pipe section was mainly influenced by axial heat conduction under boundary conditions of constant wall temperature while the region near the inlet was mainly influenced under boundary conditions of variable wall temperature. With the increasing thickness of wax deposition layer, the influence of axial heat conduction became more conspicuous. All in all, in laboratory flow loop experiment of wax deposition, although axial heat conduction had an influence on the temperature profile inside wax deposition layer under different conditions, the influence was small, thus could be ignored.
\end{abstract}

Keywords: wax deposition layer, two-dimensional heat transfer model, temperature profile, boundary conditions.

\section{INTRODUCTION}

For waxy crude oil with high freezing point, high viscosity, and poor mobility, its transportation generally uses heated oil pipeline. During the transportation, because oil temperature at initial station is higher than the ambient temperature, the oil temperature continues to decrease, and when it decreases to the wax precipitation point of crude oil, wax crystal in crude oil starts to precipitate, grow, and deposit on the pipe wall finally. Sediments on pipeline will reduce the effective flow area of the pipeline, increase friction, and thus reduce transmission capacity of the pipeline. Therefore, accurate prediction of wax deposition on pipeline has an important significance for the formulation of pigging program and safe, economical transportation of waxy crude oil in pipeline (Hsu and Santamaria, 1994; Pedersen, 1995).

Wax deposition prediction has always been a hot and important research topic for scholars at home and abroad (Hunt, 1962; Matlach et al.,1983; Agrawal et al.,1990; Bern et al., 1980; Burger and Perkins, 1981; Brown, Niesen and Erickson, 1993; Svendsen, 1993; Nazar et al, 2001; Mehrotra and Bhat, 2007; Zhang and Liu, 2010; RamirezJaramillo et al., 2004; Ribeiro et al., 1997; Lee, 2008).Based on respective purposes of measurement, scholars developed many equipments for measuring the amount of sediments on pipeline, including cold finger, cold plate, rotating disk and flow loop which was used more often than others. Through these devices, scholars had acquired some achievements. Early studies suggested that, the mechanism of wax deposition could be summarized as the following four types: molecular diffusion, shear dispersion, Brownian diffusion and gravity settling, in which molecular diffusion was generally considered as the most important mechanism causing wax deposition.
Through flow loop experiment Singh (2000) confirmed that shear dispersion, Brownian diffusion and gravity settling had little influence on wax deposition, namely molecular diffusion was dominant mechanism of wax deposition; Hamouda and Davidsen (1995) considered that shear dispersion had an influence on wax deposition, but the main cause was still molecular diffusion, and he ignored the influence of shear dispersion when establishing the prediction model of wax deposition. Establishing the prediction model of wax deposition rate to study wax deposition on pipeline was one of the effective methods. Based on the mechanism of molecular diffusion, Bern, Burger, and Brown put forward their own prediction model of wax deposition rate on pipeline respectively, and validated with field data, but each prediction model had their own application range and limitations. In addition, wax deposition was affected by many factors and, hence, wax deposition on actual pipeline couldn't be completely accurate predicted currently. Based on a large number of experimental and theoretical studies, scholars continued to study the mechanism of wax deposition.

Recently, scholars proposed the mechanism of "aging", which was widely recognized by the industry. Singh and Fogler (2000) considered that: the process of wax deposition could be described by the following steps: (1). Gelation of the waxy oil on the cold surface, (2). Diffusion of waxes towards the gel layer from the bulk, (3). Internal diffusion of these molecules through the trapped oil, (4). Precipitation of these molecules in the deposit, (5). Counterdiffusion of de-waxed oil out of the gel layer. This view was confirmed by measuring the carbon number distribution in the sample of wax deposition layer under different experimental time. Based on the mechanism of molecular diffusion, Fogler research group developed WMP (Michigan Wax Prediction) wax deposition prediction software. This software could predict the growth and wax content of the gel deposit on externally

\footnotetext{
* Corresponding Author. E-mail: believemetoo@sina.com.
} 
cooled pipe walls. As we all know, radial concentration gradient of wax molecule is an important parameter in calculating the amount of wax deposition, and it is affected by the distribution law of temperature profile of crude oil in pipe. Therefore, the calculation of temperature profile from the center of oil flow in pipe to the surface of sediments and temperature profile inside wax deposition layer is particularly important. Currently, temperature profile from the center of oil flow in pipe to the surface of sediments was more studied by scholars (Svendsen, 1993; Zhang, 2009; Huang, 2000; Singh et al., 2001; Hoffmann and Amundsen, 2009; Patankar, 1980; Flajolet et al., 1994; Aiyejina et al., 2011; Bidmus, 2003; Bidmus et al., 2004; Banki et al., 2008; Nazar et al., 2005; Venkatesan and Fogler, 2004; Lee et al., 1997), however, the special study of temperature profile inside wax deposition layer was rarely reported. Taking into account that the wax deposition layer was too thin, when calculating the temperature profile inside wax deposition layer, Singh assumed that the heat conduction inside wax deposition layer was one-dimensional based on past experience and practice (the axial heat conduction can be ignored when axial distance is much larger than radial distance). However, whether the axial heat conduction can be ignored or not when calculating temperature profile inside wax deposition layer is worthy of further verification. Therefore we believe that, abandoning previous experience and practice, studying this problem by using the related heat transfer theory of pipe is necessary.

In this article, aiming at this problem, on the basis of considering axial heat conduction inside wax deposition layer, a two-dimensional heat transfer model of calculating the temperature profile inside wax deposition layer in flow loop experiment at a time was deduced and established by using energy balance equations, and the influence of the axial heat conduction on the distribution law of temperature profile inside wax deposition layer under different boundary conditions and thickness of wax deposition layer was studied. Finally, a comparative analysis of the calculation results of one-dimensional heat transfer model and two-dimensional heat transfer model was made. The calculation results showed that: In laboratory flow loop experiment of wax deposition Although axial heat conduction had an influence on the distribution law of temperature profile inside wax deposition layer under different conditions, the influence was quite small, thus could be ignored.

\section{CALCULATION MODEL OF TEMPERATURE PROFILE INSIDE WAX DEPOSITION LAYER}

After a period of flow loop experiment, there would be sedimentary layer with certain thickness on the inner pipe wall. According to mechanism of "aging", the main component of sedimentary layer close to the inner pipe wall was paraffin wax while the main components of sedimentary layer near the center of the oil flow were asphaltenes, resins, pour point oil and other impurities (Singh and Fogler, 2000). As the temperature profile inside wax deposition layer influenced the growth rate of wax content inside wax deposition layer directly, thereby affecting the calculation of wax deposition rate and, hence, in this article, the distribution law of temperature profile inside wax deposition layer was the main research object.

\subsection{One-dimensional heat transfer model}

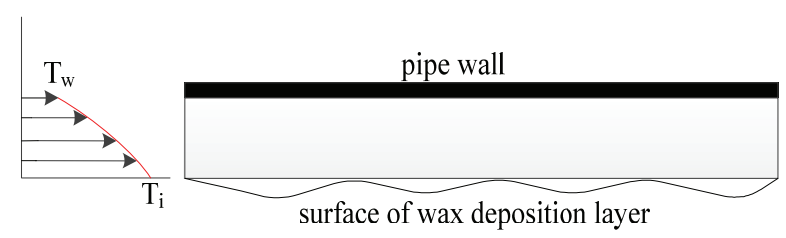

Fig. 1 Wax deposition layer on the pipe wall
Considering the wax deposition layer was too thin, when calculating the temperature profile from surface of wax deposition layer to the inner pipe wall, Singh made some assumptions as follows:

1) diffusion; particulate deposition mechanisms such as particle diffusion and gravity settling are neglected.

2) The extent of shear removal of the gel deposited in the flow loop is negligible.

3) All processes are assumed to be quasi-steady state.

4) Heat transfer from the oil-gel interface to the cold pipe-wall is a one-dimensional heat transfer.

5) There is no radial variation in the wax content of the thin gel deposit.

6) The thermal conductivity of the gel is a function of its wax content.

The schematic diagram of this model is shown in Fig. 1, and the energy equation is shown in equation (1).

$$
\frac{d^{2} T}{d r^{2}}+\frac{1}{r} \frac{d T}{d r}=0
$$

\subsection{Two-dimensional heat transfer model}

In order to establish the two-dimensional heat transfer model, some assumptions are also needed to make as follows:

1) The dominant mechanism of wax deposition is molecular diffusion, ignoring the influence of other mechanisms.

2) The wax deposition layer on the pipe wall is uniform.

3) Wax deposition experiment is conducted under steady and laminar flow condition.

Physical model of calculating temperature profile inside wax deposition layer is shown in Fig. 2.

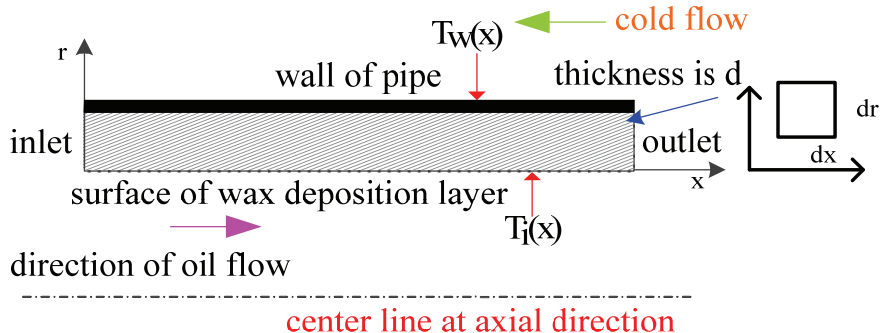

Fig. 2 Physical model of calculating the temperature profile

As for the micro unit in Fig. 2, the following equation is given based on the law of conservation of energy (Patankar, 1980):

Heat flow into micro unit + the power caused by external force on micro unit= Increasing amount of thermodynamic energy of the micro unit

By introducing Fourier heat conduction law, the energy equation expressed by specific enthalpy of fluid $h$ and temperature $T$ is:

$\frac{\partial(\rho h)}{\partial t}+\frac{\partial(\rho u h)}{\partial x}+\frac{\partial(\rho v h)}{\partial y}+\frac{\partial(\rho w h)}{\partial z}=-p \operatorname{div} U+\operatorname{div}(\lambda \operatorname{grad} T)+\Phi+S$

As for heat conduction inside wax deposition layer, the heat source $S$ is zero; dissipated energy $\Phi$ is zero; the power ( $p \operatorname{div} U)$ done by surface forces on the micro unit can be ignored generally; $h$ is taken as $h=C_{p} T$ and $C_{p}$ as a constant. Therefore, formula (2) can be expressed as:

$\operatorname{div}(U T)=\operatorname{div}\left(\frac{\lambda}{\rho C_{p}} \operatorname{grad} T\right)$ 
In cylindrical coordinates, temperature variation along the circumferential direction is zero, therefore the formula can be written as: $u \frac{\partial T}{\partial x}=\frac{1}{r} \frac{\partial T}{\partial r}+\frac{\partial^{2} T}{\partial r^{2}}+\frac{\partial^{2} T}{\partial x^{2}}$

As for the heat conduction inside wax deposition layer, $u$ is zero, namely:

$0=\frac{1}{r} \frac{\partial T}{\partial r}+\frac{\partial^{2} T}{\partial r^{2}}+\frac{\partial^{2} T}{\partial x^{2}}$

Formula (3) is the equation of calculating temperature profile inside wax deposition layer that has been deduced in this article.

The difference between these two models is that the former has the item of axial heat conduction $\frac{\partial^{2} T}{\partial x^{2}}$. Scholars generally consider that, as for the axial heat conduction $\frac{\partial^{2} T}{\partial x^{2}}$, besides the fluid (e.g. liquid metal) whose $\operatorname{Pr}$ (Prandtl number) $<<1$, the axial heat conduction can be ignored (Zhang, 2009; Singh, 2001). But in this article, the study objective is wax deposition layer on pipe wall, which cannot be treated as fluid simply. Therefore, how it affected the distribution law of temperature profile inside wax deposition layer was explored when calculating temperature profile inside wax deposition layer in this article.

\section{SOLUTION OF THE MODEL}

\subsection{The calculation of surface temperature of the wax deposition layer}

When calculating the temperature profile inside wax deposition layer, the surface temperature of wax deposition layer should be obtained first. Experimental determination of the surface temperature of wax deposition layer is relatively difficult, so it is usually obtained by the calculation of heat balance equation. Steps of calculating the surface temperature of wax deposition layer are shown below.

It can be known from the heat balance that the heat flux of oil flow at the surface of wax deposition layer is equal to the heat flux of the wax deposition layer, namely:

$\left.\lambda_{0} \frac{\partial T}{\partial r}\right|_{r=R-d}=\frac{T_{w}-T_{i}}{\frac{R-d}{\lambda} \ln \frac{R}{R-d}}$ (1993):

The calculation of oil temperature in pipe is given by Svendsen

$T(r, x)=T_{0}+\frac{T_{i}(x)-T_{0}}{0.893} \int_{\eta}^{\infty} \exp \left(-\eta^{3}\right) d \eta$

Therefore,

$\frac{\partial T}{\partial r}=\frac{T_{i}(x)-T_{0}}{0.893} \frac{e^{-\eta^{3}}}{\sqrt[3]{9 \beta x}}$

where $\eta=\frac{R-r}{\sqrt[3]{9 \beta x}}, \quad \beta=\frac{\alpha R}{2 u_{\max }}, \alpha=\frac{\lambda}{\rho C_{p}}$.

Substituting formula (5) into (4) can obtain:

$$
\frac{T_{i}(x)-T_{0}}{0.893} \frac{\lambda_{0}}{\sqrt[3]{9 \beta x}}=\frac{T_{w}-T_{i}(x)}{\frac{R-d}{\lambda} \ln \frac{R}{R-d}}
$$

Let $\frac{R-d}{\lambda} \ln \frac{R}{R-d}=A, \frac{\lambda_{0}}{0.893 \sqrt[3]{9 \beta x}}=B$, the above formula can be simplified as:

$T_{i}(x)=\frac{T_{w}+A \cdot B T_{0}}{A \cdot B+1}$

The surface temperature of wax deposition layer $T_{i}(x)$ can be obtained from equation (6).

\subsection{Analytical solution of one-dimensional heat transfer model}

As for the one-dimensional heat transfer model, the solution can be obtained by substituting boundary conditions into the model after integral. The general solution of equation (1) is:

$T=C_{1} \ln r+C_{2}$

Boundary conditions:

$\left\{\begin{array}{l}r=r_{1}, T=T_{i} \\ r=r_{2}, T=T_{w}\end{array}\right.$

The specific solution of equation (1) can be obtained by substituting the boundary conditions into equation (1), as shown in formula (7).

$T=\frac{T_{w}-T_{i}}{\ln \frac{r_{2}}{r_{1}}} \ln r+\frac{T_{i} \ln r_{2}-T_{w} \ln r_{1}}{\ln \frac{r_{2}}{r_{1}}}$

The solution of one-dimensional heat transfer model is relatively simple, the following focuses on the solution of two-dimensional heat transfer model established in this article.

\subsection{The solution of two-dimensional heat transfer model}

As for equation (3), it can be solved by separation of variables, obtaining its analytical solution, or solved numerically by finite difference method. Finite difference method is based on difference principle, through the discretization of the solved region and differential equations, linear equations of unknown function on network nodes in the solved region can be obtained, and then approximate solution of partial differential equations can be obtained by solving algebraic equations. Generally, finite difference method can solve related problems well when it is very difficult to obtain the analytical solution in solving a problem (Flajolet et al, 1994). Calculation steps of analytical solutions of the two-dimensional heat transfer model in this article were complicated and, hence, the finite difference method was used to solve the model here.

Steps of the solution of the two-dimensional heat transfer model through finite difference method are as follows:

1) The discretization of the calculation region. The calculation region is meshed by rectangle, as shown in Fig. 3.

2) The discretization of two-dimensional heat transfer equation 
According to the characteristic of equation (3), the central difference is used to discrete the equation and the equation can be discretized into the following format according to the computational grid in Fig. 3:

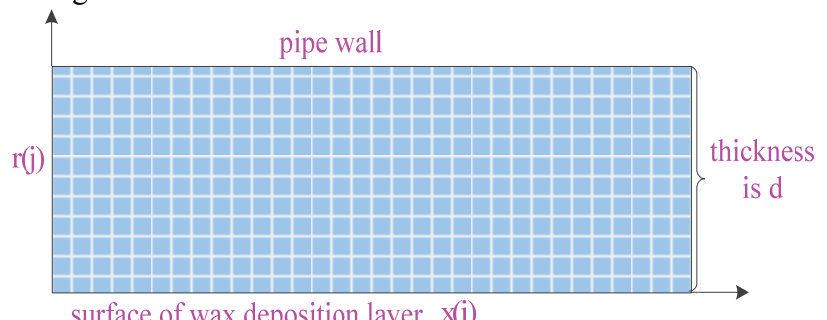

Fig. 3 The mesh generation of calculation region

$$
\frac{1}{r_{j}} \frac{T_{i, j+1}-T_{i, j-1}}{2 \Delta r}+\frac{T_{i, j+1}-2 T_{i, j}+T_{i, j-1}}{\Delta r^{2}}+\frac{T_{i+1, j}-2 T_{i, j}+T_{i-1, j}}{\Delta x^{2}}=0
$$

Letbe $a=\frac{\Delta r^{2}}{\Delta x^{2}}, \quad b=2+2 a$, thus the above formula can be transformed into:

$$
T_{i, j}=\frac{1+\frac{\Delta r}{2 r_{j}}}{b} T_{i, j+1}+\frac{1-\frac{\Delta r}{2 r_{j}}}{b} T_{i, j-1}+\frac{a}{b} T_{i-1, j}+\frac{a}{b} T_{i+1, j}
$$

Letbe $C_{1}=\frac{1+\frac{\Delta r}{2 r_{j}}}{b}, C_{2}=\frac{1-\frac{\Delta r}{2 r_{j}}}{b}, C_{3}=\frac{a}{b}=C_{4}$, finally, the equation can be transformed into:

$$
T_{i, j}=C_{1} T_{i, j+1}+C_{2} T_{i, j-1}+C_{3} T_{i-1, j}+C_{4} T_{i+1, j}
$$

The boundary conditions can be discretized though the same method, that is, assign nodes at boundary according to the boundary conditions sequentially.

3) Solution of the equations

Formula (8) is the five-point difference format of Laplace equation. Formula (8) can be solved by substituting boundary conditions into the model.

In this article, the calculation region was evenly meshed by rectangle, and the axial grid number was 100 , radial grid number was 80. First, assigned an initial value to each grid node, and then calculated equation (8) based on the differential equation, though multiple iterative calculations the temperature did not change on the whole (achieved the required accuracy) finally, the results at this point was the final calculation temperature.

\section{RESULTS AND DISUSSION}

In flow loop experiment of wax deposition, there are two types of boundary conditions which are often used generally, that is, the first type of boundary condition and the second type of boundary condition (Patankar, 1980).In the flow loop experiment of wax deposition in literature (Zhang,2009; Huang, 2000), the heat transfer coefficient of wax deposition layer and the temperature distribution of pipe wall could be measured by experiment, the radial temperature of wax deposition layer at the inlet and outlet could be measured though one-dimensional heat transfer model, that is, the temperature at each boundary of wax deposition layer were all known at a time, the boundary conditions at this situation could be regarded as the first type of boundary condition.
When calculating the temperature profile inside wax deposition layer, different boundary conditions have different influence on calculation results of temperature profile, and the continuously increasing thickness of wax deposition layer also has an influence on the distribution law of temperature profile inside wax deposition layer. The influence of axial heat conduction on the temperature profile inside wax deposition layer under different boundary conditions (constant wall temperature and variable wall temperature) and different thickness of wax deposition layer $(0.2 \mathrm{~mm}, 0.3 \mathrm{~mm}, 0.5 \mathrm{~mm})$ were discussed in the followings. For the sake of discussion, the inlet and outlet of testing pipe section of the flow loop was defined as left boundary and right boundary respectively, surface of wax deposition layer was defined as down boundary, pipe wall was defined as up boundary.

\subsection{The influence of axial heat conduction under boundary conditions of constant wall temperature}

When Huang (2000) performed the flow loop experiment of wax deposition, temperature of the external pipe wall was maintained at a constant value, which meant the variation of wall temperature along the axial direction was small when the test pipe section was short, therefore the axial wall temperature could be considered as constant approximately, that was, the boundary conditions of constant wall temperature. The related experimental parameters are shown in Table 1

Table 1 Relative parameters of the flow loop experiment.

\begin{tabular}{|c|c|c|c|c|}
\hline Parameters & $T_{0}\left({ }^{\circ} \mathrm{C}\right)$ & $T_{\text {in }}\left({ }^{\circ} \mathrm{C}\right)$ & $T_{\text {out }}\left({ }^{\circ} \mathrm{C}\right)$ & $d(\mathrm{~mm})$ \\
\hline Values & 19 & 17 & 17 & $0.2,0.3,0.5$ \\
\hline
\end{tabular}

According to the above parameters and the assumptions made previously, the boundary conditions of these two models were determined first. As for one-dimensional heat transfer model, temperature at the left and right boundary could be determined though surface temperature of wax deposition layer calculated by formula (6) and experimentally measured temperature of pipe wall, and the calculation results were in line with logarithmic law. As for twodimensional heat transfer model, since the influence of axial heat conduction was only considered inside wax deposition layer, temperature at each boundary was not affected, so the temperature at boundary of one-dimensional heat transfer model could still be used to calculate the two-dimensional heat transfer model, that was, temperature at boundary of these two models was consistent, so temperature at the left and the right boundary were still in line with logarithmic law.

Table 2 The up and down boundary when wall temperature is constant.

\begin{tabular}{|c|c|c|}
\hline $\begin{array}{c}\text { Position of } \\
\text { boundary }\end{array}$ & $d(\mathrm{~mm})$ & Temperature distribution $\left({ }^{\circ} \mathrm{C}\right)$ \\
\hline \multirow{3}{*}{$\begin{array}{c}\text { Down } \\
\text { boundary }\end{array}$} & 0.2 & $\begin{array}{r}\mathrm{T}_{\mathrm{i}}(\mathrm{x})=0.1372 \mathrm{x}^{5}-0.5144 \mathrm{x}^{4}+0.679 \mathrm{x}^{3}- \\
0.287 \mathrm{x}^{2}-0.2622 \mathrm{x}+17.31\end{array}$ \\
\cline { 2 - 3 } & 0.3 & $\begin{array}{r}\mathrm{T}_{\mathrm{i}}(\mathrm{x})=0.1235 \mathrm{x}^{3}+0.0556 \mathrm{x}^{2}-0.4278 \mathrm{x} \\
+17.44,0 \leq \mathrm{x} \leq 0.9\end{array}$ \\
& $\begin{array}{r}\mathrm{T}_{\mathrm{i}}(\mathrm{x})=0.2778 \mathrm{x}^{2}-0.8833 \mathrm{x}+17.76, \\
0.9 \leq \mathrm{x} \leq 1.5\end{array}$ \\
\cline { 2 - 3 } & 0.5 & $\mathrm{~T}_{\mathrm{i}}(\mathrm{x})=0.1461 \mathrm{x}^{2}-0.5331 \mathrm{x}+17.648$ \\
\hline Up boundary & $0.2,0.3,0.5$ & \multicolumn{2}{c}{$\mathrm{T}_{\mathrm{w}}(\mathrm{x})=17$} \\
\hline
\end{tabular}

When thickness of wax deposition layer changes, surface temperature of wax deposition layer can be calculated by formula (6), namely the corresponding down boundary. Because of the boundary conditions of constant wall temperature, temperature of pipe wall (up boundary) is constant, as shown in Table 2 . 
According to the experimental data obtained by author and size parameters of flow loop, taking the thickness of $0.2 \mathrm{~mm}$ of wax deposition layer as example, the distribution law of temperature profile inside wax deposition layer under boundary conditions of constant wall temperature was explored here.

The distribution law of temperature profile inside wax deposition layer was studied based on the coordinate shown in Fig. 2. When calculating the radial concentration gradient of wax molecule inside wax deposition layer, radial temperature gradient inside wax deposition layer often needed to be calculated, and this required to study the radial variation of temperature inside wax deposition layer at different axial positions. Because the nodes in calculation region were massive, in order to analyze the calculation results of one-dimensional heat transfer model and two-dimensional heat transfer model at different positions, temperature at three representative positions were taken along the axis direction of pipeline, which was at a distance of $0.135 \mathrm{~m}$ (near the inlet), $0.735 \mathrm{~m}$ (in the middle region) and $1.335 \mathrm{~m}$ (near the outlet) from the inlet of test pipe section throughout the whole test pipe section $(1.5 \mathrm{~m})$, then a comparative analysis of the distribution law of radial temperature at these three axial positions inside wax deposition layer was made, as shown in Fig. 4.

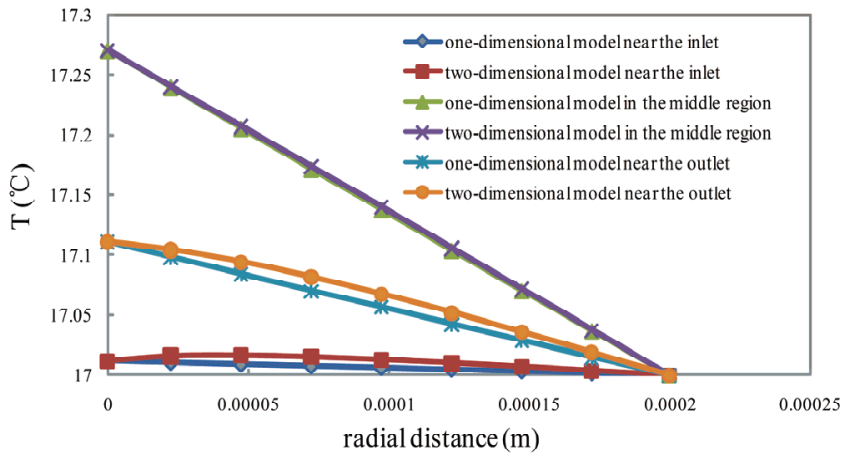

Fig. 4 Calculation results of radial temperature inside wax deposition layer at different axial positions.

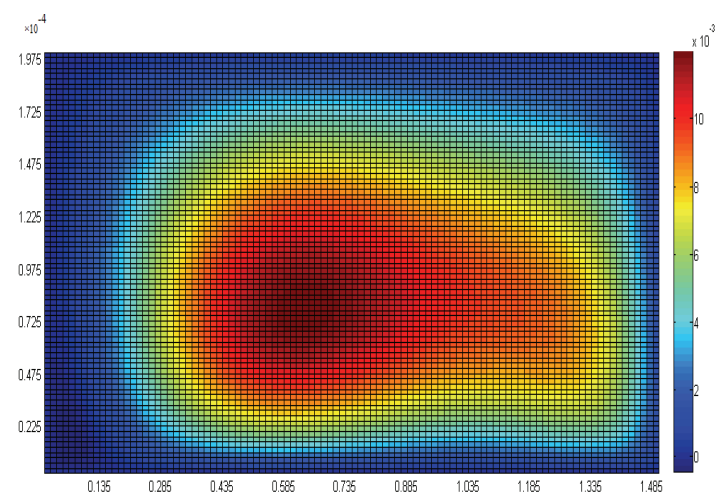

Fig. 5 Distribution of difference of the calculation temperature between the two models inside wax deposition layer.

It can be seen from Fig. 4 that radial temperature inside wax deposition layer at each axial position shows a decreasing trend. Near the inlet and outlet of the test pipe section, there is almost no difference between the results of the two models, while the difference is relatively larger in the middle region of wax deposition layer.

In the flow loop experiment, oil temperature was higher than temperature of cooling water, therefore axial temperature of pipe wall showed an increasing trend while the temperature of pipe wall was constant under boundary conditions of constant wall temperature, and calculation temperatures at different positions inside wax deposition layer were different compared with the boundary conditions of variable wall temperature in this situation. Due to the effect of cooling water, oil temperature decreased continually, there was a relatively bigger difference of the calculation temperature at somewhere inside wax deposition layer between the two models resulting from the combined effect of boundary conditions of constant wall temperature and axial heat conduction. It can be seen from the calculation results in this article that, it is in the middle region, but the difference is still small (the biggest difference is about $0.01^{\circ} \mathrm{C}$ ).

It can be seen from Fig. 5 that the calculation results of the two models have little difference, that is, axial heat conduction has little effect on the distribution law of temperature profile inside wax deposition layer, thus can be ignored

\subsection{The influence of axial heat conduction under boundary conditions of variable wall temperature}

The experimental data obtained by Zhang (2009) is quoted in this article, and the related experimental parameters are shown in Table 3.

Table 3 Parameters of the flow loop experiment.

\begin{tabular}{|c|c|c|c|c|}
\hline Parameters & $T_{0}\left({ }^{\circ} \mathrm{C}\right)$ & $T_{\text {in }}\left({ }^{\circ} \mathrm{C}\right)$ & $T_{\text {out }}\left({ }^{\circ} \mathrm{C}\right)$ & $d(\mathrm{~mm})$ \\
\hline Values & 45 & 40.5 & 40 & 0.2 \\
\hline
\end{tabular}

It was found that when fitting the temperature distribution at the up boundary by the experimentally measured temperature of pipe wall, high accuracy $\left(R^{2}=1\right)$ could be achieved with linear fitting, but at the down boundary, in order to meet the fitting accuracy, segmental fitting was used here, with the fitting accuracy were $R^{2}=0.9998$ and $R^{2}=1$ respectively, as shown in Table 4 .

Table 4 The up and down boundary when wall temperature is variable.

\begin{tabular}{|c|c|}
\hline $\begin{array}{c}\text { Position of } \\
\text { boundary }\end{array}$ & Temperature distribution $\left({ }^{\circ} \mathrm{C}\right)$ \\
\hline Up boundary & $\mathrm{T}_{\mathrm{w}}=40.5-0.1053 \mathrm{x}$ \\
\hline Down & $\mathrm{T}_{\mathrm{i}}=4.9978 \mathrm{x}^{6}-19.12 \mathrm{x}^{5}+29.792 \mathrm{x}^{4}-24.432 \mathrm{x}^{3}+11.455 \mathrm{x}^{2}-$ \\
$3.3241 \mathrm{x}+41.339,0 \leq \mathrm{x} \leq 1$ \\
boundary & $\mathrm{T}_{\mathrm{i}}=-0.0021 \mathrm{x}^{3}+0.0256 \mathrm{x}^{2}-0.2189 \mathrm{x}+40.899,1 \leq \mathrm{x} \leq 4.75$ \\
\hline
\end{tabular}

Like the analysis steps under boundary conditions of constant wall temperature, temperature at three representative positions were taken along the axis direction of pipeline, which was at a distance of $0.4275 \mathrm{~m}$ (near the inlet), $2.3275 \mathrm{~m}$ (in the middle region) and $4.2275 \mathrm{~m}$ (near the outlet) from the inlet of test pipe section throughout the whole test pipe section $(4.75 \mathrm{~m})$, then a comparative analysis of the distribution law of radial temperature at these three axial positions inside wax deposition layer was made, the results are shown in Fig. 6.

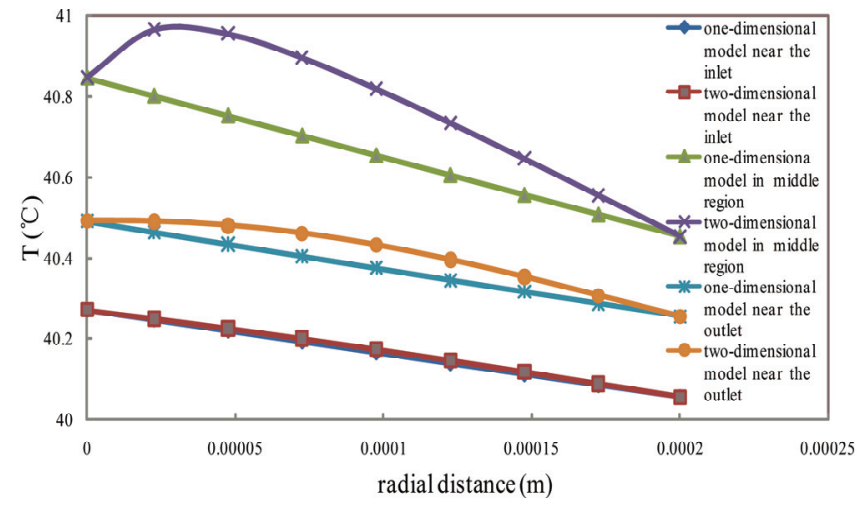

Fig. 6 Calculation results of radial temperature inside wax deposition layer at different axial positions 
It can be seen from Fig. 6 that there are some differences near the inlet between the results of the two models while no difference at other regions. Therefore in this case, axial heat conduction mainly influences the distribution law of temperature profile near the inlet of wax deposition layer, which is the same with the influence of axial heat conduction on the heat transfer law when fluid flows with low Pr number.

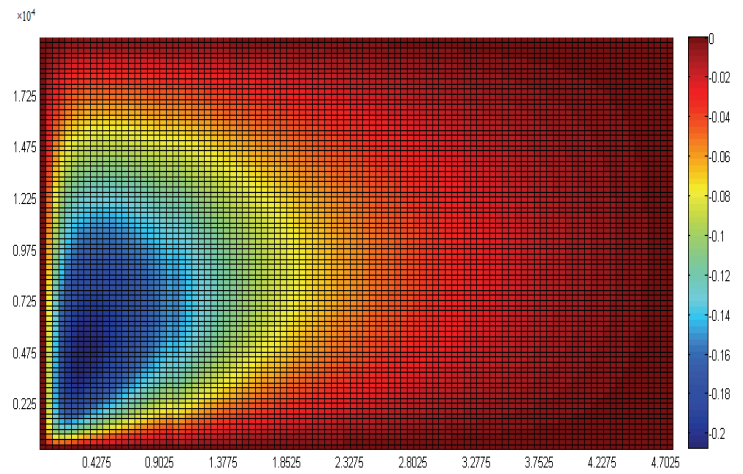

Fig. 7 Distribution of difference of the calculation temperature between the two models inside wax deposition layer

Near the inlet, the result of two-dimensional heat transfer model is larger than that of one-dimensional heat transfer model, the reasons for this difference are: in the flow loop experiment of wax deposition, because oil temperature near the inlet of testing pipe section was higher than the external cooling water temperature, hot oil in testing pipe section transferred heat to external cooling water continuously through the wax deposition layer and pipe wall under the effect of temperature difference, in the situation of considering axial heat conduction, besides radial heat conduction inside wax deposition layer, axial heat conduction was also ongoing, therefore the calculation temperature was higher than one-dimensional heat transfer model, and with the continuously increasing axial distance, the effect of axial heat conduction weakened gradually, calculation temperature of the two models at this point were of no difference, that is, the effect of axial heat conduction at other regions which were far away from the inlet was not conspicuous.

Difference of the calculation temperature between the two models inside wax deposition layer can be clearly seen from Fig. 7. The largest difference of the calculation temperature between the two models near the inlet is about $0.2^{\circ} \mathrm{C}$, larger than other regions. Therefore, when calculating temperature profile inside wax deposition layer, special attention should be paid to the region near the inlet, where the influence of axial heat conduction is relatively larger. Overall, the difference of calculation temperature between the two models is small, but the twodimensional heat transfer model reflects the actual heat transfer inside wax deposition layer better.

Under the boundary conditions of variable wall temperature, the influence of axial heat conduction on the distribution law of temperature profile inside wax deposition layer at the thickness of $0.3 \mathrm{~mm}, 0.5 \mathrm{~mm}$ of wax deposition layer is almost same with the thickness of $0.2 \mathrm{~mm}$, therefore no detailed discussion here.

\subsection{The influence of axial heat conduction at different thickness of wax deposition layer}

In order to discuss the influence of thickness of wax deposition layer on calculation results of temperature profile, temperature profile inside wax deposition layer at the thickness of $0.3 \mathrm{~mm}$ and $0.5 \mathrm{~mm}$ were also calculated. Under boundary conditions of constant wall temperature, like the analysis steps at the thickness of $0.2 \mathrm{~mm}$, temperature at three representative positions were taken along the axis direction of pipeline, which was at a distance of $0.135 \mathrm{~m}$ (near the inlet), $0.735 \mathrm{~m}$ (in the middle region) and $1.335 \mathrm{~m}$ (near the outlet) from the inlet of test pipe section throughout the whole test pipe section $(1.5 \mathrm{~m})$, then a comparative analysis of the calculation temperature at these three representative positions at different thickness of the two models was made, as shown in Fig. 8.

In can be seen from Fig. 8 that the distribution law of temperature profile inside wax deposition layer (the thickness of wax deposition layer is $0.3 \mathrm{~mm}$ and $0.5 \mathrm{~mm}$ ) is consistent with that of the thickness of $0.2 \mathrm{~mm}$. At different axial positions (near the inlet, in the middle region, near the outlet), the influence of axial heat conduction on the distribution law of temperature profile inside wax deposition layer of different thickness is different, the differences are relatively larger in the middle region while little near the inlet and outlet. As for the two models, the radial temperature inside wax deposition layer at same axial position increases with the increasing thickness of wax deposition layer. This is because that when the thickness of wax deposition layer increases, the distance between surface of wax deposition layer and center of oil fluid becomes small, thus the temperature of wax deposition layer becomes higher. The larger the thickness of wax deposition layer, the more conspicuous of the effect of axial heat conduction, thereby the larger difference of calculation results of the two models.

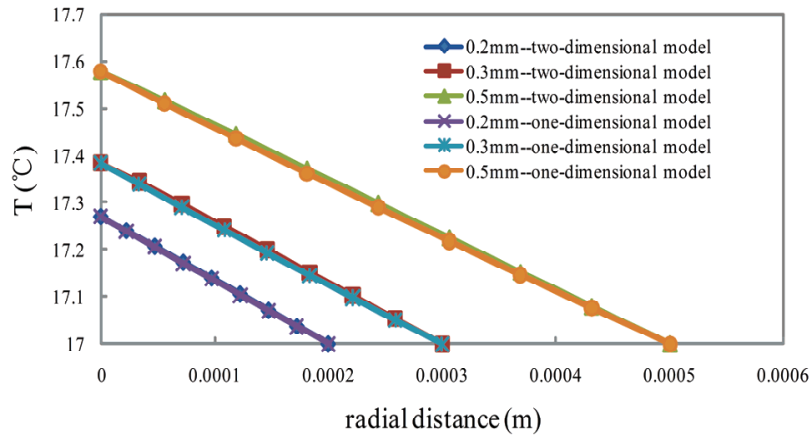

(a) near the inlet.

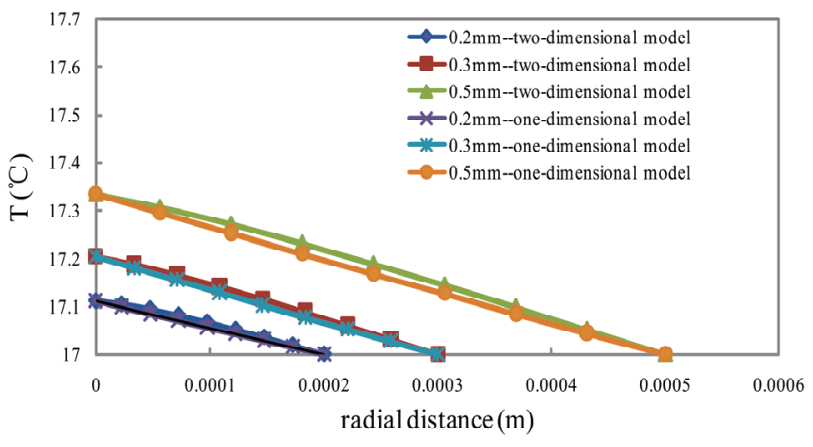

(b) in the middle region.

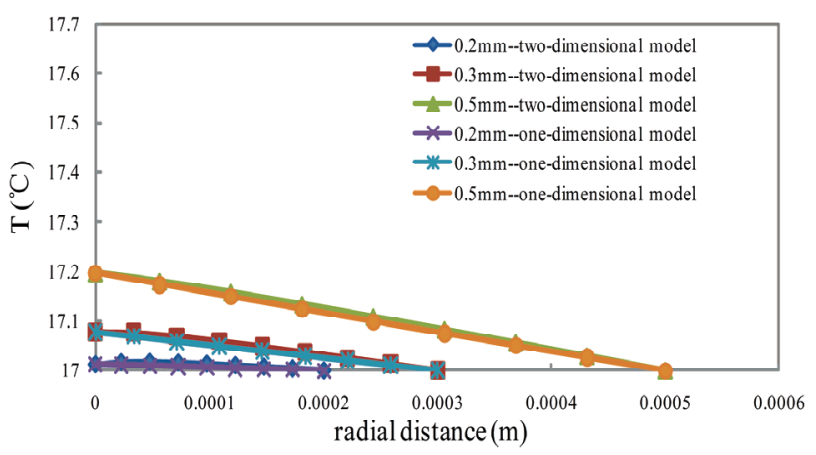

(c) near the inlet.

Fig. 8 The calculation temperature of the two models at different thickness and boundary conditions of constant wall temperature 
In order to analyze the effect of axial heat conduction on the distribution law of temperature profile inside wax deposition layer at different thickness more clearly, the difference of calculation results of the two models are shown in Fig. 9. It can be seen from Fig. 9 that the differences of calculation results of the two models at each representative positions are relatively small, with the largest difference is less than $0.025^{\circ} \mathrm{C}$ (c in Fig. 9), therefore, the effect of axial heat conduction can still be ignored at different thickness of wax deposition layer under boundary conditions of constant wall temperature.

Under the boundary conditions of variable wall temperature, the influence of axial heat conduction on the distribution law of temperature profile inside wax deposition layer at different thickness of wax deposition layer is same with that under the boundary conditions of constant wall temperature, therefore no detailed discussion here.

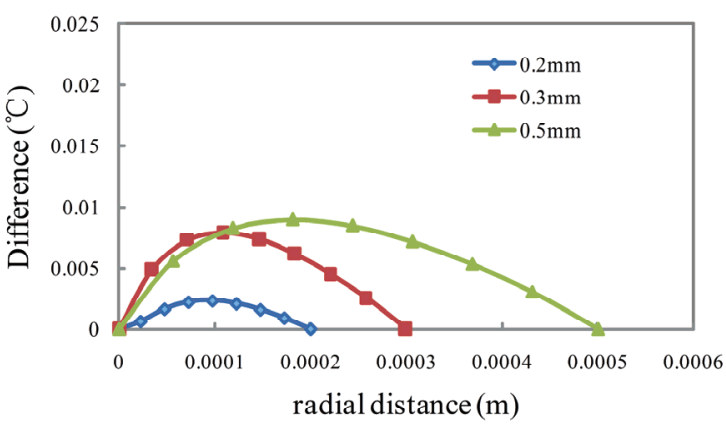

(a) near the inlet.

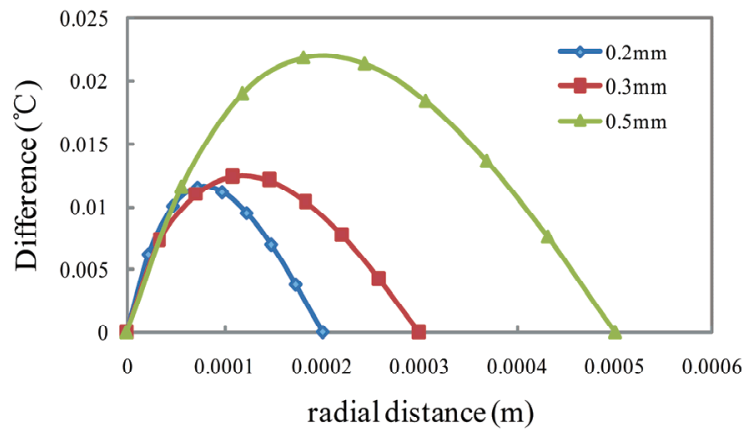

(b) in the middle region.

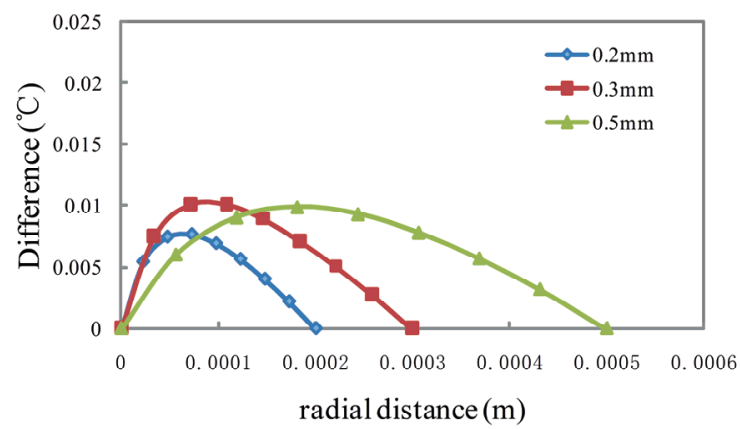

(c) near the outlet.

Fig. 9 The difference of calculation results of the two models at different thickness and axial positions

\section{CONCLUSIONS}

The distribution law of temperature profile inside wax deposition layer is the key to study wax deposition rate of crude oil in pipeline. As for this problem, the influence of axial heat conduction inside wax deposition layer was always ignored in previous studies, however, whether the influence on calculating temperature inside wax deposition layer was large or not was worthy of further verification when the axial heat conduction was ignored.

In this article, a two-dimensional heat transfer model of calculating temperature profile inside wax deposition layer in the flow loop experiment at a time was deduced and established by using energy balance equations, and the influence of the axial heat conduction on the distribution law of temperature profile inside wax deposition layer under different conditions was studied, then comparative analysis with the calculation results of one-dimensional heat transfer model was made. The calculation results showed that: the influence of axial heat conduction under boundary conditions of variable wall temperature was mainly embodied near the inlet of testing pipe section while the influence was relatively small in other regions; under boundary conditions of constant wall temperature, influenced by the combined effect of boundary conditions of constant wall temperature and axial heat conduction, the difference of calculation temperature of the two models was relatively larger in the middle region; at three types of thickness of the wax deposition layer given above, the influence of axial heat conduction became more conspicuous with the increasing thickness of wax deposition layer. Overall, in laboratory flow loop experiment, although axial heat conduction had an influence on the distribution law of temperature profile inside wax deposition layer, the influence was quite small. This method was also applicable to practical pipeline, and the concrete situations needed a further study based on field data and the two dimensional heat transfer model obtained in this work. From theoretical point of view, it was confirmed in this article that ignoring axial heat conduction in the calculation of temperature profile inside wax deposition layer was entirely feasible.

\section{NOMENCLATURE}

$T_{i} \quad$ surface temperature of wax deposition layer, ${ }^{\circ} \mathrm{C}$

$T_{w} \quad$ temperature of pipe wall, ${ }^{\circ} \mathrm{C}$

$r_{l} \quad$ distance from the center of oil flow to surface of wax deposition layer, $\mathrm{m}$

$r_{2} \quad$ distance from surface of wax deposition layer to pipe wall, $\mathrm{m}$

$l \quad$ length of wax deposition layer (length of pipe), $\mathrm{m}$

$d \quad$ thickness of wax deposition layer at a time, $\mathrm{mm}$

$u \quad$ velocity of fluid $(\mathrm{m} / \mathrm{s})$

$C_{p} \quad$ specific heat $(\mathrm{J} / \mathrm{kg} \cdot \mathrm{K})$

$R \quad$ inner radius of pipe, $\mathrm{m}$

$T_{0} \quad$ oil temperature at the inlet, ${ }^{\circ} \mathrm{C}$

$T_{\text {in }} \quad$ wall temperature at the inlet, ${ }^{\circ} \mathrm{C}$

$T_{\text {out }} \quad$ wall temperature at the outlet, ${ }^{\circ} \mathrm{C}$

$C_{p} \quad$ specific heat $(\mathrm{J} / \mathrm{kg} \cdot \mathrm{K})$

\section{Greek Symbols}

$\lambda$ heat conduction coefficient of wax deposition layer, $\mathrm{W} /(\mathrm{m} \cdot \mathrm{K})$

$\lambda_{0} \quad$ heat conduction coefficient of crude oil, $\mathrm{W} /(\mathrm{m} \cdot \mathrm{K})$

$\rho \quad$ density $\left(\mathrm{kg} / \mathrm{m}^{3}\right)$

\section{REFERENCES}

Agrawal, K.M., Khan, H.U., Surianarayanan, M., Joshi, G.C., 1990, "Wax Deposition of Bombay High Crude Oil under Flowing Conditions," Fuel, 69, 794-796.

http://dx.doi.org/10.1016/0016-2361(90)90051-Q

Aiyejina, A., Dhurjati, P.C., Pilgrim, A., Sastry, M.K.S., 2011, "Wax Formation in Oil Pipelines: A Critical Review," International Journal of Multiphase Flow, 37, 671-694.

http://dx.doi.org/ 10.1016/j.ijmultiphaseflow.2011.02.007

Banki, R., Hoteit, H., Firoozabadi, A., 2008, "Mathematical Formulation and Numerical Modeling of Wax Deposition in Pipelines 
from Enthalpy-porosity Approach and Irreversible Thermodynamics," International Journal of Heat and Mass Transfer, 51, 3387-3398. http://dx.doi.org/ 10.1016/j.ijheatmasstransfer.2007.11.012

Bern, P.A., Withers, V.R., Cairns, J.R., 1980, "Wax Deposition in Crude Oil Pipelines," 206-1980-MS, European Offshore Petroleum Conference and Exhibition, London.

http://dx.doi.org/10.2118/206-1980-MS

Bidmus, H.O., 2003, "A Thermal Study of Wax Deposition from Paraffinic Mixtures," M.Sc. Thesis, University of Calgary, Calgary, Canada.

Bidmus, H.O., Mehrotra, A.K., 2004, "Heat-Transfer Analogy for Wax Deposition from Paraffinic Mixtures," Ind. Eng. Chem. Res, 43, 791803.

http://dx.doi.org/ 10.1021/ie030573v

Brown, T.S., Niesen, V.G., Erickson, D.D., 1993, "Measurement and Prediction of Kinetics of Paraffin Deposition," 26548-MS, SPE Annual Technical Conference and Exhibition, Houston, Texas.

http://dx.doi.org/10.2118/26548-MS

Burger, E.D., Perkins, T.K., Striegler, J.H., 1981, "Studies of Wax Deposition in the Trans-Alaska Pipeline," Journal of Petroleum Technology, 33, 1075-1086.

http://dx.doi.org/10.2118/8788-PA

Flajolet, P., Sedgewick, R., 1994, "Mellin Transforms and Asymptotics: Finite Differences and Rice's Integrals," Theoretical Computer Science, 144, 101-124.

http://dx.doi.org/10.1016/0304-3975(94)00281-M

Hamouda, A.A., Davidsen, S., 1995, “An Approach for Simulation of Paraffin Deposition in Pipelines as a Function of Flow Characteristics with a Reference to Teesside Oil Pipeline," 28966-MS, SPE International Symposium on Oilfield Chemistry, San Antonio, Texas. http://dx.doi.org/10.2118/28966-MS

Hoffmann, R., Amundsen, L., 2009, "Single-Phase Wax Deposition Experiments," Energy and Fuels, 24, 1069-1080.

http://dx.doi.org/ 10.1021/ef900920x

Hsu, J.J.C., Santamaria, M.M., Brubaker, J.P., 1994, "Wax Deposition of Waxy Live Crudes under Turbulent Flow Condition," 28480-MS, SPE Annual Technical Conference and Exhibition, New Orleans, Louisiana.

http://dx.doi.org/10.2118/28480-MS

Hunt, E.B.Jr., 1962, "Laboratory Study of Paraffin Deposition," Journal of Petroleum Technology, 14, 1605-1612.

http://dx.doi.org/ 10.2118/279-PA

Huang, Q.Y., 2000, "The Study of Dynamics Model of Wax Deposition of Waxy Crude Oil in Pipe," Ph.D. Thesis, China University of Petroleum (Beijing), Beijing, China.

Lee, H.S., 2008, "Computational and Rheological Study of Wax Deposition and Gelation in Subsea Pipelines," Ph.D. Thesis, The University of Michigan, Michigan, United States.

Lee, K.S., Kim, W.S., Lee, T.H., 1997, “A One-Dimensional Model for Frost Formation on a Cold Flat Surface," International Journal of Heat and Mass Transfer, 40, 4359-4365.

http://dx.doi.org/ 10.1016/S0017-9310(97)00074-4
Matlach, W.J., Newberry, M.E., 1983, "Paraffin Deposition and Rheological Evaluation of High Wax Content Altamont Crude Oils," 11851-MS, SPE Rocky Mountain Regional Meeting, Salt Lake City, Utah.

http://dx.doi.org/ 10.2118/11851-MS

Mehrotra, A.K.., Bhat, N.V., 2007, "Modeling the Effect of Shear Stress on Deposition from "Waxy" Mixtures under Laminar Flow with Heat Transfer," Energy and Fuels, 21, 1277-1286.

http://dx.doi.org/ 10.1021/ef060445u

Nazar, A.R.S, Dabir, B., Islam, M.R., 2005, "Experimental and Mathematical Modeling of Wax Deposition and Propagation in Pipes Transporting Crude Oil," Energy Sources, 27, 185-207.

http://dx.doi.org/ 10.1080/00908310490448262

Nazar, A.R.S, Dabir, B., Islam, M.R., 2001, "Measurement and Modeling of Wax Deposition in Crude Oil Pipelines," 69425-MS, SPE Latin American and Caribbean Petroleum Engineering Conference, Buenos Aires, Argentina.

http://dx.doi.org/ 10.2118/69425-MS

Patankar, S.V., 1980, "Numerical Heat Transfer and Fluid Flow," Hemisphere Publishing Corporation, Washington, DC.

Pedersen, K.S., 1995, "Prediction of Cloud Point Temperatures and Amount of Wax Precipitation," SPE Production and Facilities, 10, 4649.

http://dx.doi.org/10.2118/27629-PA

Ramirez-Jaramillo, E., Lira-Galeana, C., Manero, O., 2004, "Modeling Wax Deposition in Pipelines," Petroleum Science and Technology, 22, 821-861.

http://dx.doi.org/ 10.1081/LFT-120038726

Ribeiro, F.S., Mendes, P.R.S., Braga, S.L., 1997, "Obstruction of Pipelines due to Paraffin Deposition during the Flow of Crude Oils," International Journal of Heat Mass Transfer, 18, 4319-4328.

http://dx.doi.org/ 10.1016/S0017-9310(97)00082-3

Singh, P., Venkatesan, R., Fogler, H.S., Nagarajan N., 2000, "Formation and Aging of Incipient Thin Film Wax-Oil Gels," AIChE Journal, 46, 1059-1074.

http://dx.doi.org/ 10.1002/aic.690460517

Singh, P., Venkatesan, R., Fogler, H.S., Nagarajan N., 2001, "Morphological Evolution of Thick Wax Depositions during Aging," AIChE Journal, 47, 6-18.

http://dx.doi.org/ 10.1002/aic.690470103

Svendsen, J.A., 1993, "Mathematical Modeling of Wax Deposition in Oil Pipeline Systems,” AIChE Journal, 39, 1377-1388.

http://dx.doi.org/ 10.1002/aic.690390815

Venkatesan, R., Fogler, H.S., 2004, "Comments on Analogies for Correlated Heat and Mass Transfer in Turbulent Flow," AIChE Journal, 50, 1623-1626.

http://dx.doi.org/ 10.1002/aic.10146

Zhang, G.Z., Liu, G., 2010, "Study on the Wax Deposition of Waxy Crude in Pipelines and Its Application," Journal of Petroleum Science and Engineering, 70, 1-9.

http://dx.doi.org/ 10.1016/j.petrol.2008.11.003

Zhang, Z.B., 2009, "Wax Deposition Property of Waxy Oil in Pipeline," Ph.D. Thesis, China University of Petroleum (Huadong), Dongying, China. 